\title{
The Psychometric Properties of the Bangla Posttraumatic Stress Disorder Checklist for DSM-5 (PCL-5): A Large-scale Validation Study
}

Md. Saiful Islam ( $\square$ islam.msaiful@outlook.com )

Jahangirnagar University

Most. Zannatul Ferdous

Jahangirnagar University

Md. Safaet Hossain Sujan

Jahangirnagar University

Rafia Tasnim

Jahangirnagar University

Jakir Hossain Bhuiyan Masud

Public Health Informatics Foundation

Sourav Kundu

Advanced Institute of Industrial Technology

Abu Syed Md. Mosaddek

Uttara Adhunik Medical College

M. Shahabuddin K. Choudhuri

Jahangirnagar University

Ibrahim A. Kira

Georgia State University

David Gozal

University of Missouri

\section{Research Article}

Keywords: PTSD, PCL-5, Bangla, depression, confirmatory factor analysis

Posted Date: February 19th, 2021

DOI: https://doi.org/10.21203/rs.3.rs-210877/v1

License: (c) (1) This work is licensed under a Creative Commons Attribution 4.0 International License.

Read Full License 


\section{Abstract}

Background: The Posttraumatic Stress Disorder Checklist (PCL-5) is the most widely used screening tool in assessing posttraumatic stress disorder symptoms, based on the Diagnostic and Statistical Manual of Mental disorders (DSM-5) criteria. This study aimed to evaluate the psychometric properties of the newly translated Bangla PCL-5.

Methods: A cross-sectional survey was carried out among 10,605 individuals (61.0\% male; mean age: 23.6 \pm 5.5 [13-71 years]) during May and June 2020, several months after the onset of the COVID-19 outbreak in Bangladesh. The survey included Bangla PCL-5 and PHQ-9 depression scale. We used confirmatory factor analysis to test the four-factor DSM-5 model, the six-factor Anhedonia model, and the seven-factor Hybrid model.

Results: Bangla PCL-5 displayed adequate internal consistency (Cronbach's alpha $=0.90)$. The Bangla PCL-5 score was significantly correlated with scores of the PHQ-9 depression scale. Confirmatory factor analyses indicated the models had a good fit to the data, including the four-factor DSM-5 model, the sixfactor Anhedonia model, and the seven-factor Hybrid model.

Conclusions: The Bangla PCL-5 appears to be a valid and reliable psychometric screening tool that may be employed in the prospective evaluation of posttraumatic stress disorder in Bangladesh.

\section{Introduction}

Posttraumatic stress disorder (PTSD) is a common psychiatric condition associated with a stressful experience, and has emerged as a major burden to those affected and to society [1]. Troubles with sleeping, somatic chronic pain, depression, drug abuse, adverse interpersonal relations, and reduced overall wellness are characteristic of PTSD [2, 3]. PTSD follows traumatic events characterized by a typical intrusion symptom pattern, persistence of trauma, inappropriate recruitment of preventative stimuli, physiological and emotional numbness, and hypersensitivity [4].

The Posttraumatic Stress Disorder Checklist (PCL) has long been the leading self-reported instrument for assessing PTSD symptoms [5, 6]. Since the popularization of the most recent edition of the Diagnostic and Statistical Manual of Mental Disorders (DSM-5), the PCL has been updated to incorporate additional symptoms and to conform with the four-factor PTSD conceptualization of the DSM and its associated symptom clusters: re-experiencing, avoidance, negative changes in cognition and mood, and increased arousal and reactivity. $[6,7]$. This transition from the previously outlined three-factor PTSD model in DSMIV [8], is based on a substantial body of empirical data indicating that this four-factor model better fits the composition of PTSD symptomatology $[9,10]$.

The PCL-5 [11] consists of 20 items corresponding to the 20 criteria for PTSD outlined in the DSM-5, and includes 4 subscales referring to the 4 symptom clusters mentioned above. It is de facto a modified version of the PCL-4 containing 17 items and three subscales referring to the former three symptom 
clusters of the DSM-IV [5]. Earlier research on the psychometric properties of PCL-5 has been promising. In a study of college students, PCL-5 illustrated positive and significant correlation, proper test reliability, as well as converging and divergent validity [12]. Such findings are comparable to the psychometric findings in previous versions of the measure [13] and suggest that the PCL-5 has the same psychometric rigor as the previous versions. Preliminary findings on the appropriate PCL- 5 cut-off scores were mixed, and reported values ranging from 28 to $38[11,12]$. Earlier versions of the PCL were available in multiple languages [14]. However, as far as we know, PCL-5 is still available in only a few, limited number of languages.

COVID-19 was first reported in Bangladesh on March 8th, 2020 [15], and similar to many other countries rapidly propagated, with more than 310,800 people infected and 4,248 deaths as of August 31st, 2020 $[16,17]$. To reduce the spread of SARS-CoV-2, the Government of Bangladesh imposed strict social isolation, home quarantine, and restricted travel measures starting as of March 26th, 2020 [15, 18]. Experiencing or witnessing the suffering imposed by COVID-19 can cause PTSD among survivors, their families, frontline workers, and even the general public [19]. It is further anticipated that the COVID-19 pandemic will result in a high prevalence of psychological problems at the population level, including PTSD [20], and previous studies involving outbreaks of SARS in 2003 [21] and influenza A H1N1 in 2009 [22] have corroborated such assumption.

In the context of COVID-19, this pandemic will likely impose major adverse effects on mental health, and yet there few if any studies addressing these issues in Bangladesh, as illustrated by the use of a previously not validated tool in a study that was conducted among the survivors of Rana Plaza collapse [2]. To better address this important problem, the PCL-5 was translated to Bangla language, and in the current study, we present the validation of this instrument. As indicated above, the PCL- 5 is one of the most widely used self-report measures of PTSD [12]. In an earlier study, Islam et al. (2020) suggested the need to conduct a nationwide survey to investigate PTSD symptoms and prevalence during the COVID-19 pandemic. The present study was designed to explore the presence of acute posttraumatic stress symptoms among Bangladeshi people in the several months that have followed the onset of the COVID19 outbreak in the country, and to ascertain whether the Bangla version of the PCL-5 is suitable for the Bangladeshi cultural framework as a screening instrument.

\section{Methodology}

\section{Study design and participants}

This present research study utilized a cross-sectional study design with a sample of 10,605 individuals and conducted between May and June 2020, i.e., nearly 3 months after the onset of the COVID-19 outbreak in Bangladesh. A self-reported anonymous questionnaire with informed consent was developed and administered online after informed consent. The targeted participants were representative of the general population of Bangladesh and could speak and understand Bangla. Individuals approached who suffered from mental or physical issues or who were unwilling to participate were not included. 


\section{Study procedure and adaption of PCL-5 into Bangla}

A convenience sampling technique was implemented, but in light of the pandemic situation, the survey questionnaire was conceived and published online. The questionnaire took roughly 10 to 15 minutes to complete. The PTSD Checklist for DSM-5 (PCL-5) questionnaire was translated using the widest used guideline [i.e. Beaton et al. (2000)] [23]. Firstly, the questionnaire was translated into Bangla (participants' language) by 3 expert translators, who after reaching consensus on this final Bangla version, the latter was then back-translated into English (i.e., forward-backward translation) by 3 additional translators. All the copies of the questionnaire were then evaluated and approved by a four-member expert panel including a psychologist, epidemiologist, psychiatrist, and linguistic experts. A conceptual translation was implemented instead of a literal translation to ensure that the original meaning of an item was preserved while adapting it to the Bangladeshi cultural context.

A pilot test was initially conducted to check the reliability of the questionnaire using 100 participants. Then, using Google Survey Tool and with the help of research assistants selected from different areas of Bangladesh to ensure a high response rate, a web-based survey was carried out. Initially, 10,850 respondents have submitted the survey form after obtaining informed consent. Of these, 10,664 (98.3\%) respondents completed the entire survey. After eliminating surveys that were completed but had data missing, 10,605 surveys were included in the final analysis.

\section{Measures}

To obtain information from participants, a semi-structured self-reported survey questionnaire was used containing an informed consent form, and questions concerning socio-demographic and psychometric

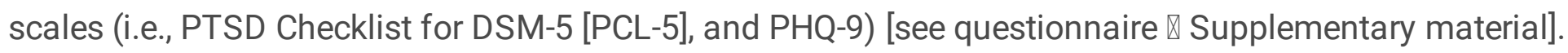

\section{Socio-demographic measures}

During the survey, socio-demographic data were collected by asking questions regarding age, sex, education, occupation, marital status, type of family (nuclear versus joint/extended), monthly family income, residence (rural versus urban), and smoking habits (yes/no). The monthly family income was categorized into the following three classes based on their monthly total family income in Bangladeshi Taka (BDT): $<15,000$ BDT, 15,000-30,000 BDT, and >30,000 BDT [24, 25].

\section{PTSD Checklist for DSM-5 (PCL-5)}

The Bangla translated version of the PTSD Checklist for DSM-5 (PCL-5) is, exactly as the original English version, a self-reported 20 -item scale, and evaluates the presence, severity, and 20 symptoms related to PTSD in the Diagnostic and Statistical Manual of Mental Disorders (5th edition; DSM-5) [11]. The scale represents the extent to which an individual is suffering from posttraumatic stress disorder. Respondents were asked to fill up the scale in the questionnaire following their feelings in the last month (e.g., "Repeated, disturbing, and unwanted memories of the stressful experience"), on a five-point Liker scale, which ranges from 0 to 4: 0 "Not at all", 1 "A little bit", 2 "Moderately", 3 "Quite a bit", 4 "Extremely". The 
final score was obtained by summating the 20 items, such that the final score ranges from $0-80$. It includes four subscales; i) re-experience (5 symptoms), ii) avoidance (2 symptoms), iii) negative alterations in cognition and mood (7 symptoms), and iv) alterations in arousal and reactivity (6 symptoms). A PCL-5 cut-off score of 31 to 33 has been suggested to diagnose likely PTSD and exhibits $88 \%$ sensitivity, and $69 \%$ specificity [26]. In the present study, the Bangla PCL-5 scale was found to have excellent reliability (Cronbach's alpha $=0.90$ ).

\section{Patient Health Questionnaire (PHQ-9)}

The Patient Health Questionnaire (PHQ-9) is the most widely used self-reported screening tool for assessing the severity of depressive disorders [27]. This scale comprises nine items with a four-point Likert scale ranging from 0 ("Not at all") to 3 ("Nearly every day"). Each item refers to problems experienced including issues with sleep, exhaustion, changes in appetite, difficulties with concentration, and suicidal thoughts are measured over the past two weeks (e.g., "Little interest or pleasure in doing things'). The level of depression varies into four groups as minimal, mild, moderate, moderately severe, and severe based on scoring $0-4,5-9,10-14,15-19$, and 20-27 points, respectively. The present study employed the previously validated Bangla PHQ-9 questionnaire to investigate the level of participants' depressive disorders [28] which has been extensively used [29-31]. In the present study, the PHQ-9 scale was found to have very good reliability (Cronbach's alpha $=0.89$ ).

\section{Statistical analysis}

The data were analyzed using Microsoft Excel 2019, IBM SPSS Statistics version 25, and IBM SPSS Amos version 23. Descriptive statistics (e.g., frequencies, percentages, means, standard deviations, etc.) were performed using SPSS software. To investigate the validity and reliability of the Bangla PCL-5, its properties were examined and reported both at item-level and scale level.

\section{Reliability}

For the item-level analysis, item distribution (i.e., means, standard deviations), skewness, and kurtosis were computed and are reported. For scale-level analysis, the internal consistency of the scale was examined using reliability coefficients (i.e., Cronbach's alpha). Furthermore, composite reliability (CR), item-total correlations, and Cronbach's alpha-if item deleted, etc. were reported.

\section{Structural validity}

Confirmatory factor analysis (CFA) was executed to evaluate the structural validity of the Bangla PCL-5 instrument using SPSS Amos. The 3 most popular models were investigated for confirmatory factor analysis including the DSM-5 four-factor model (i.e., Re-experiencing [B1-B5], Avoidance [C1-C2], Negative alterations in cognitions and mood [D1-D7], and Alterations in arousal and reactivity [E1-E6]); the sixfactor Anhedonia model (i.e., Re-experiencing [B1-B5], Avoidance [C1-C2], Negative affect [D1-D4], Anhedonia [E1-E3], Dysphoric arousal [H1-H2], Anxious arousal [E1-E2], and Dysphoric arousal [H3-H4]) [32]; and the seven-factor Hybrid model (i.e., Re-experiencing [B1-B5], Avoidance [C1-C2], Negative affect 
[D1-D4], Anhedonia [E1-E3], Externalizing behaviors [F1-F2], Anxious arousal [G1-G2], and Dysphoric arousal [H1-H2]) [33].

In all of the CFA models, the chi-square $\left(\chi^{2}\right)$, the Root Mean Square Error of Approximation (RMSEA), the Standardized Root Mean Square Residual (SRMR), the Comparative Fit Index (CFI), the Normed Fit Index (NFI), Tucker Lewis Fit Index (TLI), Goodness of Fit Index (GFI), and Adjusted Goodness of Fit (AGFI) were calculated using SPSS Amos. Thresholds and conventional fit indices were applied to investigate the goodness of fit of the model under statistical analysis: RMSEA $(0.05 ; 0.08)$, SRMR $(0.05 ; 0.08), \mathrm{CFI}$ (0.90:0.95), GFI (0.90;0.95), AGFI (0.90;0.95), TLI (0.90;0.95), and NFI (0.90;0.95) [34-37].

\section{Criterion validity}

The criterion validity of the Bangla PCL-5 instrument was evaluated by reporting its correlations with the related instrument (i.e., PHQ-9). Furthermore, the convergent validity was assessed via correlations between the PCL-5 subscales and PHQ-9. Earlier studies reported high correlations ranging from 0.70 to 0.77 between PTSD and depression symptoms using PCL-5 and PHQ-9 instruments [26, 38-40].

\section{Ethical considerations}

All procedures of this study were carried out in keeping with the principles of Institutional Research Ethics and The Code of Ethics of the World Medical Association involving human subjects (Declaration of Helsinki). Formal ethics approval was granted by the Ethical Review Committee, Uttara Adhunik Medical College, Uttara, Dhaka, Bangladesh. All data were collected anonymously, and all participants consented to the survey willingly. The consent form was clearly outlined and included i) the purpose and process of the research, ii) aims and objectives of the research, iii) data anonymity and privacy, iv) option to participate in the study, and v) right to withdraw data from studies at any time.

\section{Results}

\section{General characteristics of participants}

A total of 10,605 respondents were included in the final analysis, of which $61.0 \%$ were male with an average age of $23.6 \pm 5.5$ years, ranging from 13 to 71 years. A sizeable portion of respondents were students $(75.2 \%)$, and unmarried (84.0\%), and had a bachelor's degree level of education $(67.9 \%)$ (Table 1). Moreover, the majority of the responders came from urban areas (63.1\%), lived in nuclear families (78.9\%), and had monthly family income above 30,000 BDT (45.3\%). A sizeable portion of respondents reported as being non-smokers (84.6\%). 
Table 1

General characteristics of participants $(N=10,605)$

\begin{tabular}{|lll|}
\hline Characteristics & $\mathbf{n}$ & $\mathbf{( \% )}$ \\
\hline Sex & & \\
\hline Male & 6472 & $(61.0)$ \\
\hline Female & 4133 & $(39.0)$ \\
\hline Educational qualification & & \\
\hline No academic education & 84 & $(0.8)$ \\
\hline Primary (1-5 grades) & 51 & $(0.5)$ \\
\hline Secondary (6-10 grades) & 281 & $(2.6)$ \\
\hline Intermediate (11-12 grades) & 1562 & $(14.7)$ \\
\hline Bachelor & 7202 & $(67.9)$ \\
\hline Higher education (above bachelor) & 1425 & $(13.4)$ \\
\hline Occupation & & \\
\hline Student & 7976 & $(75.2)$ \\
\hline Private employee & 828 & $(7.8)$ \\
\hline Government employee & 342 & $(3.2)$ \\
\hline Housewife & 303 & $(2.9)$ \\
\hline Businessman & 263 & $(2.5)$ \\
\hline Freelancer & 164 & $(1.5)$ \\
\hline Farmer & 59 & $(0.6)$ \\
\hline Day laborer & 39 & $(0.4)$ \\
\hline Unemployed & 478 & $(4.5)$ \\
\hline Retired & & $(0.2)$ \\
\hline Doctor & & $(0.5)$ \\
\hline Others & & $(0.8)$ \\
\hline Marital status & & \\
\hline Single & & \\
\hline Married & & \\
\hline Divorced & & \\
\hline
\end{tabular}




\begin{tabular}{|lll|}
\hline Characteristics & $\mathbf{n}$ & (\%) \\
\hline Family type & & \\
\hline Nuclear & 8369 & $(78.9)$ \\
\hline Join & 2236 & $(21.1)$ \\
\hline Monthly family income & & \\
\hline$<15,000$ BDT & 1983 & $(18.7)$ \\
\hline $15,000-30,000$ BDT & 3817 & $(36.0)$ \\
\hline$>30,000$ BDT & 4805 & $(45.3)$ \\
\hline Residence & & \\
\hline Urban area & 6696 & $(63.1)$ \\
\hline Rural area & 3909 & $(36.9)$ \\
\hline Smoking habits & & \\
\hline Yes & 1634 & $(15.4)$ \\
\hline No & 8971 & $(84.6)$ \\
\hline
\end{tabular}

\section{Reliability}

Table 2 presents the mean, standard deviation, item-total correlation, Cronbach's alpha of the scale if each item is omitted, as well as Skewness and Kurtosis of each translated PCL-5 item. The inter-item correlation matrix (Table 2) contained no negative values, indicating that the items were assessing the same construct. All items yielded Skewness and Kurtosis values within the \pm 2.0 range, indicating that they were normally distributed. 
Table 2

Mean, standard deviation, item-total correlation, Skewness, Kurtosis, and Cronbach's alpha of the scale for each translated PCL-5 item.

\begin{tabular}{|c|c|c|c|c|c|c|c|}
\hline $\begin{array}{l}\text { PCL-5 } \\
\text { item }\end{array}$ & Mean & SD & Median & $\begin{array}{l}\text { Item-total } \\
\text { correlation }\end{array}$ & Skewness & Kurtosis & $\begin{array}{l}\text { Cronbach's a if } \\
\text { Item Deleted }\end{array}$ \\
\hline 1 & 2.13 & 1.208 & 2 & 0.428 & 0.039 & -1.137 & 0.894 \\
\hline 2 & 1.02 & 1.133 & 1 & 0.538 & 1.040 & 0.184 & 0.891 \\
\hline 3 & 1.95 & 1.261 & 2 & 0.430 & 0.209 & -1.149 & 0.894 \\
\hline 4 & 2.14 & 1.295 & 2 & 0.491 & 0.016 & -1.254 & 0.892 \\
\hline 5 & 0.90 & 1.108 & 1 & 0.545 & 1.155 & 0.455 & 0.891 \\
\hline 6 & 1.72 & 1.223 & 1 & 0.403 & 0.324 & -0.918 & 0.895 \\
\hline 7 & 1.68 & 1.279 & 1 & 0.389 & 0.347 & -0.967 & 0.895 \\
\hline 8 & 0.99 & 1.133 & 1 & 0.499 & 1.010 & 0.081 & 0.892 \\
\hline 9 & 1.22 & 1.274 & 1 & 0.586 & 0.815 & -0.451 & 0.889 \\
\hline 10 & 1.02 & 1.203 & 1 & 0.530 & 1.014 & -0.030 & 0.891 \\
\hline 11 & 1.48 & 1.284 & 1 & 0.557 & 0.534 & -0.829 & 0.890 \\
\hline 12 & 1.45 & 1.264 & 1 & 0.609 & 0.607 & -0.774 & 0.889 \\
\hline 13 & 1.62 & 1.389 & 1 & 0.605 & 0.440 & -1.140 & 0.889 \\
\hline 14 & 1.15 & 1.262 & 1 & 0.587 & 0.889 & -0.356 & 0.889 \\
\hline 15 & 1.53 & 1.336 & 1 & 0.634 & 0.525 & -0.971 & 0.888 \\
\hline 16 & 0.93 & 1.192 & 0 & 0.501 & 1.123 & 0.154 & 0.892 \\
\hline 17 & 1.57 & 1.212 & 1 & 0.233 & 0.396 & -0.840 & 0.899 \\
\hline 18 & 1.23 & 1.241 & 1 & 0.629 & 0.766 & -0.518 & 0.888 \\
\hline 19 & 1.59 & 1.337 & 1 & 0.630 & 0.477 & -1.024 & 0.888 \\
\hline 20 & 1.36 & 1.361 & 1 & 0.548 & 0.654 & -0.878 & 0.890 \\
\hline
\end{tabular}

The coefficients of Cronbach's alpha were calculated to investigate internal consistency. Cronbach's alpha for the total PCL-5 was 0.90 , indicating excellent internal consistency. Furthermore, the CR of the Bangla PCL-5 was satisfactory ( $C R=0.93)$, which is well beyond the acceptable threshold of $0.70[41,42]$. Cronbach's alpha and CR for the total score and each of the subscales of the Bangla PCL-5 instrument are presented in Tables 3 and 4, respectively. 
Table 3

The mean, standard deviation, median of total scores, and Cronbach's alpha of each scale/subscale

\begin{tabular}{|lllll|}
\hline Scale/subscale & Item $(\mathbf{n})$ & Mean(SD) & Median & Cronbach's a \\
\hline Total PCL-5 & 20 & $28.7(14.5)$ & 27 & 0.90 \\
\hline PCL-5 subscales & & & & \\
\hline 1.Re-experiencing & 5 & $8.1(4.3)$ & 8 & 0.750 \\
\hline 2. Avoidance & 2 & $3.4(2.1)$ & 3 & 0.576 \\
\hline 3. Cognition and mood & 7 & $8.9(6.2)$ & 8 & 0.827 \\
\hline 4. Arousal & 6 & $8.2(5.2)$ & 7 & 0.762 \\
\hline
\end{tabular}

Table 4

Psychometric properties of Bangla PCL-5

\begin{tabular}{|c|c|c|c|c|c|}
\hline Name of index & $\begin{array}{l}\text { Index } \\
\text { name }\end{array}$ & $\begin{array}{l}\text { Four-factor } \\
\text { DSM-5 } \\
\text { model }\end{array}$ & $\begin{array}{l}\text { Six-factor } \\
\text { Anhedonia } \\
\text { model }\end{array}$ & $\begin{array}{l}\text { Seven- } \\
\text { factor } \\
\text { Hybrid } \\
\text { model }\end{array}$ & $\begin{array}{l}\text { Level of } \\
\text { acceptance }\end{array}$ \\
\hline \multicolumn{6}{|l|}{ Absolute Fit } \\
\hline Discrepancy chi square & $\chi^{2}(d f)$ & 7905.8(164) & $6243.7(155)$ & $5967.0(149)$ & $p>0.05$ \\
\hline $\begin{array}{l}\text { Root Mean Square Error of } \\
\text { Approximation }\end{array}$ & RMSEA & 0.067 & 0.061 & 0.061 & $<0.08$ \\
\hline $90 \%$ Confidence interval & $90 \% \mathrm{Cl}$ & $\begin{array}{l}(0.065- \\
0.068)\end{array}$ & $\begin{array}{l}(0.060- \\
0.062)\end{array}$ & $\begin{array}{l}(0.059- \\
0.062)\end{array}$ & \\
\hline $\begin{array}{l}\text { Standardized Root Mean } \\
\text { Square Residual }\end{array}$ & SRMR & 0.05 & 0.05 & 0.05 & $<0.08$ \\
\hline The goodness of Fit Index & GFI & 0.92 & 0.93 & 0.94 & $>0.9$ \\
\hline \multicolumn{6}{|l|}{ Incremental Fit } \\
\hline Adjusted Goodness of Fit & AGFI & 0.9 & 0.91 & 0.91 & $>0.9$ \\
\hline Comparative Fit Index & $\mathrm{CFI}$ & 0.9 & 0.91 & 0.92 & $>0.9$ \\
\hline Tucker-Lewis Index & TLI & 0.9 & 0.9 & 0.9 & $>0.9$ \\
\hline Normed Fit Index & $\mathrm{NFI}$ & 0.9 & 0.91 & 0.92 & $>0.9$ \\
\hline \multicolumn{6}{|l|}{ Reliability } \\
\hline Composite Reliability & $\mathrm{CR}$ & 0.93 & 0.93 & 0.94 & $>0.6$ \\
\hline Average Variance Extracted & AVE & 0.39 & 0.39 & 0.43 & $>0.5$ \\
\hline
\end{tabular}




\section{Construct validity}

CFA was performed to appraise the structural validity of the Bangla PCL-5 instrument using the DSM- 5 four-factor model, the six-factor Anhedonia model, and the seven-factor Hybrid model. Each of the CFA models, the Absolute Fit (i.e., $\chi^{2}$, RMSEA, SRMR, GFI), and the Incremental Fit (i.e., AGFI, CFI, TLI, NFI) were observed for the model fit estimation (see Table 4). All fitness indexes were satisfactory within their conventional thresholds, which the models displaying an excellent fit to the data.

Factor loadings for each model of PCL-5 ranged between 0.52 and 0.92 (see Table 5) except item no 17. The acceptability factor was greater than the load value of 0.32 [43]. The average variance extracted (AVE) and CR was also calculated to examine convergent validity (see Table 5). The convergent validity is supported if the $C R$ is higher than 0.7 and $A V E$ is higher than 0.5 for each construct [42]. According to Fornell and Larcker, if AVE is less than 0.5 , but CR is higher than 0.6 , the convergent validity of the construct is still adequate [42]. Structural equation modeling (SEM) revealed a positive correlation between each factor in all examined three models - the DSM- 5 four-factor model, the six-factor Anhedonia model, and the seven-factor Hybrid model, respectively (see - Figs. 1-3). 
Table 5

Standardized factor loading estimates for confirmatory factor analysis models

\begin{tabular}{|c|c|c|c|c|c|c|}
\hline \multirow[t]{3}{*}{ DSM-5 symptoms } & \multirow{2}{*}{\multicolumn{2}{|c|}{$\begin{array}{l}\text { Four-factor } \\
\text { DSM-5 model }\end{array}$}} & \multirow{2}{*}{\multicolumn{2}{|c|}{$\begin{array}{l}\text { Six-factor } \\
\text { Anhedonia model }\end{array}$}} & \multirow{2}{*}{\multicolumn{2}{|c|}{$\begin{array}{l}\text { Seven-factor } \\
\text { Hybrid model }\end{array}$}} \\
\hline & & & & & & \\
\hline & Factor & $\begin{array}{l}\text { Factor } \\
\text { Loads }\end{array}$ & Factor & $\begin{array}{l}\text { Factor } \\
\text { Loads }\end{array}$ & Factor & $\begin{array}{l}\text { Factor } \\
\text { Loads }\end{array}$ \\
\hline 1. Repeated memories & $\mathbf{R}$ & 0.62 & $\mathbf{R}$ & 0.62 & $\mathbf{R}$ & 0.62 \\
\hline 2. Repeated dreams & $\mathbf{R}$ & 0.62 & $\mathbf{R}$ & 0.62 & $\mathbf{R}$ & 0.62 \\
\hline 3. Flashbacks & $\mathbf{R}$ & 0.60 & $\mathbf{R}$ & 0.60 & $\mathbf{R}$ & 0.60 \\
\hline 4. Upset when reminded & $\mathbf{R}$ & 0.68 & $\mathbf{R}$ & 0.67 & $\mathbf{R}$ & 0.67 \\
\hline $\begin{array}{l}\text { 5. Physical reaction when } \\
\text { reminded }\end{array}$ & $\mathbf{R}$ & 0.57 & $\mathbf{R}$ & 0.57 & $\mathbf{R}$ & 0.56 \\
\hline 6. Avoidance of thoughts & A & 0.66 & A & 0.66 & A & 0.66 \\
\hline 7. Avoidance of reminders & A & 0.61 & A & 0.61 & A & 0.61 \\
\hline 8. Trouble remembering & NACM & 0.52 & NA & 0.52 & NA & 0.52 \\
\hline 9. Negative beliefs & NACM & 0.67 & NA & 0.73 & NA & 0.73 \\
\hline 10. Blame of self or others & NACM & 0.60 & NA & 0.67 & NA & 0.67 \\
\hline 11. Negative feelings & NACM & 0.62 & NA & 0.67 & NA & 0.67 \\
\hline 12. Loss of interest & NACM & 0.68 & An & 0.71 & An & 0.71 \\
\hline 13. Feeling distant & NACM & 0.69 & An & 0.73 & An & 0.73 \\
\hline 14. Trouble positive feelings & NACM & 0.67 & An & 0.70 & An & 0.70 \\
\hline 15. Irritable behavior & AR & 0.74 & DA & 0.74 & EB & 0.73 \\
\hline 16. Reckless behavior & AR & 0.57 & DA & 0.56 & EB & 0.56 \\
\hline 17. Being super alert & AR & 0.21 & AA & 0.25 & AA & 0.25 \\
\hline 18. Feeling jumpy & AR & 0.71 & AA & 0.92 & AA & 0.91 \\
\hline 19. Difficulty concentrating & AR & 0.72 & DA & 0.72 & DA & 0.76 \\
\hline 20. Trouble sleeping & AR & 0.62 & DA & 0.60 & DA & 0.64 \\
\hline
\end{tabular}

\section{Criterion validity}


To evaluate the criterion validity of the PCL-5 instrument, its total, as well as its subscales correlations with the PHQ-9 instrument, are outlined in Table 6. The correlation between the PCL-5 and the PHQ-9 generated a significant and positive correlation $(r=0.7, p<0.001)$, confirming strong convergent validity. Furthermore, the correlation regarding PCL-5 subscales and PHQ-9 scale yielded a positive and statistically significant correlation in each case (i.e., Re-experiencing: $r=0.44$; Avoidance: $r=0.26$; Cognitions and mood: $r=0.67$; Arousal: $r=0.68 ; p<0.001$ for all comparisons).

Table 6

The correlations of the Bangla PCL-5 instrument and its subscales with the PHQ-9 instrument

\begin{tabular}{|lll|}
\hline Scale/subscale & PHQ-9 & $p$-value \\
\hline PCL-5 & 0.7 & $<0.001$ \\
\hline Re-experiencing & 0.44 & $<0.001$ \\
\hline Avoidance & 0.26 & $<0.001$ \\
\hline Cognition and mood & 0.67 & $<0.001$ \\
\hline Arousal & 0.68 & $<0.001$ \\
\hline
\end{tabular}

The present study aimed to translate and validate the PTSD for DSM-5 (PCL-5) in a large cohort in Bangladesh after at least nearly months from the beginning of the COVID-19 outbreak, and as such enable the use of the most widely used psychometric tool to assess post-traumatic stress disorder. The Bangla PCL-5 emerged as psychometrically sound and as a robust instrument since it demonstrated (区)

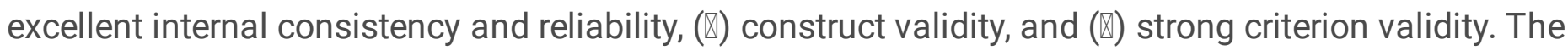
findings suggest that Bangla PCL-5 is a valid and potentially useful tool to assess post-traumatic stress disorder among Bangladeshi people.

The findings revealed excellent internal consistency of the Bangla version of PCL-5, which was similar to previous studies in different languages $[6,39,40,44-46]$. The Cronbach's alpha of the subscales of the Bangla PCL-5 was also very similar to the aforementioned studies examining translations into different languages. The inter-item correlation matrix yielded positive values across all items, indicating that these items were assessing the same construct. All items had Skewness and Kurtosis values within the \pm 2.0 range, indicating that they were normally distributed. Accordingly, the Bangla version of the PCL- 5 showed significant validity at this stage of assessment and performed similarly to previous efforts to translate the instrument in other countries.

The construct validity of the Bangla PCL-5 was also corroborated by confirmatory factor analysis using the DSM-5 four-factor model, the six-factor Anhedonia model [32], and the seven-factor Hybrid model [33]. All fitness indices were highly satisfactory within their conventional thresholds, which indicated that the models exhibited an excellent fit to the data. Moreover, composite reliability (CR) yielded factors ranging (0.93-0.94) for each model, which is well beyond the accepted threshold of 0.70 [42] and supported 
convergent validity. The average variance extracted (AVE) obtained ranges of $0.39-0.43$ for each model. Of note, and according to Fornell and Larcker, if AVE is less than 0.5 , but CR is higher than 0.6 , the convergent validity of the construct is still adequate [42].

The correlation between the PCL-5 and depression (using PHQ-9) generated a significant and positive correlation $(r=0.7, p<0.001)$, confirming strong convergent validity, a finding that has also been similarly reported in previous studies using a similar instrument (Philippines: PCL-5 vs. PHQ-9, $r=0.71$; [39]; Netherlands: PCL-5 vs. PHQ-9, $r=0.72 ;[40]$ ). A strong correlation obtained between the PCL-5 and depression using different instruments in different languages including English (PCL-5 vs. Center for Epidemiological Studies-Depression Scale [CES-D], $r=0.64$ ) [6], French (PCL-5 vs. CES-D, $r=0.62$ ) [6], Turkish (PCL-5 vs. Beck Depression Inventory, $r=0.64$ ) [44], Arab/Kurdish (PCL-5 vs. Depression Hopkins Symptom checklist, $r=0.65$ ) [47], and Swedish (PCL-5 vs. Montgomery-Asberg Depression Rating Scale, $r$ $=0.60$ ) [45] further confirms the robustness of the tool across various translations including Bangla.

\section{Limitations}

Although the psychometric properties of the Bangla PCL-5 were overall satisfactory, there are some potential limitations worthy of commentary. First, compared with face-to-face interviews, self-reporting has limitations including potential multiple biases (e.g., memory recall, social desirability biases). Secondly, the study executed a cross-sectional study design. Longitudinal observation is important, particularly given the potential for post-traumatic experiences and temporal evolution characteristics of this process. Thirdly, this was an online-based survey, so this study was not representative, for example, of those who have limited internet access or may be unwilling to respond via this methodology. Randomized prospective studies could provide potential insights into causation, although these may be complicated to conduct during a pandemic such as COVID-19.

\section{Conclusions}

To our knowledge, this is the first translation and validation of the PCL-5 into Bangla. We evaluated the comprehensive psychometric properties of this instrument in a large sample while ascertaining the contextual Bangladeshi cultural background setting. Our findings indicate that the Bangla PCL-5 appears to be a robust instrument to screen for the presence of posttraumatic stress disorders among Bangladeshi individuals. In light of the protracted course of the COVID-19 pandemic and the restrictive measures being implemented as well as the economic devastation imposed by this virus, the Bangla PCL5 instrument will aid in the assessments of posttraumatic stress disorders in Bangladesh and potentially serve as the primary screening tool for further evaluation and treatment of affected individuals.

\section{Abbreviations}

PCL-5: Posttraumatic Stress Disorder Checklist; DSM-5: Diagnostic and Statistical Manual of Mental disorders; PTSD: Posttraumatic stress disorder; COVID-19: Coronavirus disease-2019; SARS-CoV-2: Severe acute respiratory syndrome coronavirus 2; BDT: Bangladeshi Taka; PHQ: Patient Health Questionnaire; 
ANOVA: Analysis of variance; SPSS: Statistical Package for the Social Sciences; CR: composite reliability; CFA: Confirmatory factor analysis; SEM: Structural equation modeling; AVE: Average variance extracted (AVE).

\section{Declarations}

\section{Ethics approval and consent to participate}

The study was conducted in accordance with the Institutional Research Ethics guidelines and ethical guidelines involving human participation (i.e., Helsinki Declaration). Formal ethics approval was granted by Ethical Review Committee, Uttara Adhunik Medical College (Ref. No.: UAMC/ERC/ 16/2020). Informed consent was obtained from all participants or, if participants are under 18, from a parent and/or legal guardian.

\section{Consent for publication}

Not applicable.

\section{Availability of data and materials}

The datasets used and/or analyzed during the current study are available from the corresponding author on reasonable request.

\section{Competing interests}

The authors declare that they have no potential conflict of interest in the publication of this research output.

\section{Funding}

The authors didn't receive any grants or remunerations from either public or private organizations or other funding agencies.

\section{Authors' contribution}

Conceptualization: MSI, MZF, MSHS, RT. Data collection: MSI, MZF, MSHS, RT. Analysis and interpretation of data: MSI. Drafting of the manuscript: MSI, MZF, MSHS, RT. Editing: MZF, JHBM, SK, ASMM, MSKC, IAK, DG. Critical revision of the manuscript: IAK, DG. All authors have read and approved the manuscript. 


\section{Acknowledgments}

Firstly, the authors would like to express the most profound gratitude to all of the respondents who participated in this study. Secondly, the authors wish to express their sincere appreciation to all the Research Assistants of the Youth Research Association and Quest Bangladesh, Dhaka, Bangladesh, who took part in this research (see responsible individuals: http://tiny.cc/acknowledgements).

\section{References}

1. Kessler RC. Posttraumatic stress disorder: the burden to the individual and to society. J Clin Psychiatry. 2000;61 Suppl 5:4.

2. Fitch T, Villanueva G, Quadir MM, Sagiraju HKR, Alamgir H. The prevalence and risk factors of PostTraumatic Stress Disorder among workers injured in Rana Plaza building collapse in Bangladesh. Am J Ind Med. 2015;58:756-63. doi:10.1002/ajim.22471.

3. Cloitre M, Cohen LR, Edelman RE, Han H. Posttraumatic stress disorder and extent of trauma exposure as correlates of medical problems and perceived health among women with childhood abuse. Women Health. 2001;34:1-17. doi:10.1300/J013v34n03_01.

4. Deja M, Denke C, Weber-Carstens S, Schröder J, Pille CE, Hokema F, et al. Social support during intensive care unit stay might improve mental impairment and consequently health-related quality of life in survivors of severe acute respiratory distress syndrome. Crit Care. 2006;10:R147. doi:10.1186/cc5070.

5. Weathers F, Litz B, Herman D, Huska JA, Keane T. The PTSD Checklist (PCL): Reliability, validity, and diagnostic utility. Pap Present Annu Conv Int Soc Trauma Stress Stud. 1993.

6. Ashbaugh AR, Houle-Johnson S, Herbert C, El-Hage W, Brunet A. Psychometric Validation of the English and French Versions of the Posttraumatic Stress Disorder Checklist for DSM-5 (PCL-5). PLoS One. 2016;11:e0161645.

7. American Psychiatric Association. Diagnostic and statistical manual of mental disorders. Fifth Edit. Washington, DC: American Psychiatric Association; 2013.

8. American Psychiatric Association. Diagnostic and statistical manual of mental disorders. Fourth Edi. Washington, DC: American Psychiatric Association; 2000.

9. King DW, Leskin GA, King LA, Weathers FW. Confirmatory factor analysis of the clinicianadministered PTSD Scale: Evidence for the dimensionality of posttraumatic stress disorder. Psychol Assess. 1998;10:90-6.

10. Palmieri PA, Weathers FW, Difede J, King DW. Confirmatory factor analysis of the PTSD Checklist and the Clinician-Administered PTSD Scale in disaster workers exposed to the World Trade Center Ground Zero. J Abnorm Psychol. 2007;116:329-41.

11. Weathers FW, Litz BT, Keane TM, Palmieri PA, Marx BP, Schnurr PP. The ptsd checklist for dsm-5 (PCL-5). Scale available from Natl Cent PTSD www ptsd va gov. 2013;10. 
12. Blevins CA, Weathers FW, Davis MT, Witte TK, Domino JL. The Posttraumatic Stress Disorder Checklist for DSM-5 (PCL-5): Development and Initial Psychometric Evaluation. J Trauma Stress. 2015;28:489-98. doi:10.1002/jts.22059.

13. Blanchard EB, Jones-Alexander J, Buckley TC, Forneris CA. Psychometric properties of the PTSD Checklist (PCL). Behav Res Ther. 1996;34:669-73.

14. Ventureyra VAG, Yao S-N, Cottraux J, Note I, De Mey-Guillard C. The validation of the Posttraumatic Stress Disorder Checklist Scale in posttraumatic stress disorder and nonclinical subjects. Psychother Psychosom. 2002;71:47-53.

15. Islam MS, Sujan MSH, Tasnim R, Sikder MT, Potenza MN, van Os J. Psychological responses during the COVID-19 outbreak among university students in Bangladesh. PLoS One. 2020;15:e0245083.

16. Institute of Epidemiology Disease Control and Research. Covid-19 status for Bangladesh. 2020. http://old.iedcr.gov.bd/. Accessed 28 Jun 2020.

17. Worldometer. COVID-19 coronavius pandemic. 2020. https://www.worldometers.info/coronavirus/. Accessed 25 Apr 2020.

18. Islam MS, Ferdous MZ, Potenza MN. Panic and generalized anxiety during the COVID-19 pandemic among Bangladeshi people: an online pilot survey early in the outbreak. J Affect Disord. 2020;276:30-7.

19. Xiao S, Luo D, Xiao Y. Survivors of COVID-19 are at high risk of posttraumatic stress disorder. Glob Heal Res Policy. 2020;5:29. doi:10.1186/s41256-020-00155-2.

20. Shultz JM, Baingana F, Neria Y. The 2014 Ebola outbreak and mental health: current status and recommended response. JAMA. 2015;313:567-8.

21. Peng EY-C, Lee M-B, Tsai S-T, Yang C-C, Morisky DE, Tsai L-T, et al. Population-based post-crisis psychological distress: an example from the SARS outbreak in Taiwan. J Formos Med Assoc. 2010;109:524-32. doi:10.1016/S0929-6646(10)60087-3.

22. Yeung NCY, Lau JTF, Choi KC, Griffiths S. Population Responses during the Pandemic Phase of the Influenza A(H1N1)pdm09 Epidemic, Hong Kong, China. Emerg Infect Dis. 2017;23:813-5. doi:10.3201/eid2305.160768.

23. Beaton DE, Bombardier C, Guillemin F, Ferraz MB. Guidelines for the process of cross-cultural adaptation of self-report measures. Spine (Phila Pa 1976). 2000;25:3186-91.

24. Rahman ME, Islam MS, Bishwas MS, Moonajilin MS, Gozal D. Physical inactivity and sedentary behaviors in the Bangladeshi population during the COVID-19 pandemic: An online cross-sectional survey. Heliyon. 2020;6:e05392.

25. Rahman ME, Islam MS, Mamun MA, Moonajilin MS, Yi S. Prevalence and factors associated with suicidal ideation among university students in Bangladesh. Arch Suicide Res. 2020;:1-10.

26. Bovin MJ, Marx BP, Weathers FW, Gallagher MW, Rodriguez P, Schnurr PP, et al. Psychometric properties of the PTSD Checklist for Diagnostic and Statistical Manual of Mental Disorders-Fifth Edition (PCL-5) in veterans. Psychol Assess. 2016;28:1379-91. 
27. Spitzer RL, Kroenke K, Williams JB. Validation and utility of a self-report version of PRIME-MD: the PHQ primary care study. Primary Care Evaluation of Mental Disorders. Patient Health Questionnaire. JAMA. 1999;282:1737-44.

28. Chowdhury A, Ghosh S, Sanyal D. Bengali adaptation of Brief Patient Health Questionnaire for screening depression at primary care. J Indian Med Assoc. 2004;102:544-7.

29. Moonajilin MS, Rahman ME, Islam MS. Relationship between overweight/obesity and mental health disorders among Bangladeshi adolescents: a cross-sectional survey. Obes Med. 2020;18:100216.

30. Islam MS, Akter R, Sikder T, Griffiths MD. Prevalence and factors associated with depression and anxiety among first-year university students in Bangladesh: a cross-sectional study. Int J Ment Health Addict. 2020.

31. Islam MS, Rahman ME, Moonajilin MS, Griffiths MD. Validation and evaluation of the psychometric properties of Bangla nine-item Internet Disorder Scale-Short Form. J Addict Dis. 2020;38:540-9.

32. Liu P, Wang L, Cao C, Wang R, Zhang J, Zhang B, et al. The underlying dimensions of DSM-5 posttraumatic stress disorder symptoms in an epidemiological sample of Chinese earthquake survivors. J Anxiety Disord. 2014;28:345-51. doi:https://doi.org/10.1016/j.janxdis.2014.03.008.

33. Armour C, Tsai J, Durham TA, Charak R, Biehn TL, Elhai JD, et al. Dimensional structure of DSM-5 posttraumatic stress symptoms: Support for a hybrid Anhedonia and Externalizing Behaviors model. J Psychiatr Res. 2015;61:106-13. doi:https://doi.org/10.1016/j.jpsychires.2014.10.012.

34. Hu L, Bentler PM. Cutoff criteria for fit indexes in covariance structure analysis: Conventional criteria versus new alternatives. Struct Equ Model a Multidiscip J. 1999;6:1-55.

35. Bentler PM, Bonett DG. Significance tests and goodness of fit in the analysis of covariance structures. Psychol Bull. 1980;88:588.

36. Bentler PM. Comparative fit indexes in structural models. Psychol Bull. 1990;107:238.

37. Hooper D, Coughlan J, Mullen MR. Structural equation modelling: Guidelines for determining model fit. Electron J Bus Res methods. 2008;6:53-60.

38. Phelps L, Williams R, Raichle K, Turner A, Ehde D. The Importance of Cognitive Processing to Adjustment in the 1st Year Following Amputation. Rehabil Psychol. 2008;53:28-38.

39. Hall BJ, Yip PSY, Garabiles MR, Lao CK, Chan EWW, Marx BP. Psychometric validation of the PTSD Checklist-5 among female Filipino migrant workers. Eur J Psychotraumatol. 2019;10:1571378. doi:10.1080/20008198.2019.1571378.

40. Van Praag DLG, Fardzadeh HE, Covic A, Maas AIR, von Steinbüchel N. Preliminary validation of the Dutch version of the Posttraumatic stress disorder checklist for DSM-5 (PCL-5) after traumatic brain injury in a civilian population. PLoS One. 2020;15:e0231857. https://doi.org/10.1371/journal.pone.0231857.

41. Hair JF, Black WC, Babin BJ, Anderson RE, Tatham RL. Multivariate data analysis. Prentice hall Upper Saddle River, NJ; 1998. 
42. Fornell C, Larcker DF. Evaluating structural equation models with unobservable variables and measurement error. J Mark Res. 1981;18:39-50.

43. Tabachnick BG, Fidell LS. Using multivariate statistics. Boston, MA: Allyn \& Bacon/Pearson Education. 2001.

44. Boysan M, Guzel Ozdemir P, Ozdemir O, Selvi Y, Yilmaz E, Kaya N. Psychometric properties of the Turkish version of the PTSD Checklist for Diagnostic and Statistical Manual of Mental Disorders, Fifth Edition (PCL-5). Psychiatry Clin Psychopharmacol. 2017;27:300-10.

doi:10.1080/24750573.2017.1342769.

45. Sveen J, Bondjers K, Willebrand M. Psychometric properties of the PTSD Checklist for DSM-5: a pilot study. Eur J Psychotraumatol. 2016;7:30165.

46. Krüger-Gottschalk A, Knaevelsrud C, Rau H, Dyer A, Schäfer I, Schellong J, et al. The German version of the Posttraumatic Stress Disorder Checklist for DSM-5 (PCL-5): psychometric properties and diagnostic utility. BMC Psychiatry. 2017;17:379.

47. Ibrahim H, Ertl V, Catani C, Ismail AA, Neuner F. The validity of Posttraumatic Stress Disorder Checklist for DSM-5 (PCL-5) as screening instrument with Kurdish and Arab displaced populations living in the Kurdistan region of Iraq. BMC Psychiatry. 2018;18:259.

\section{Figures}




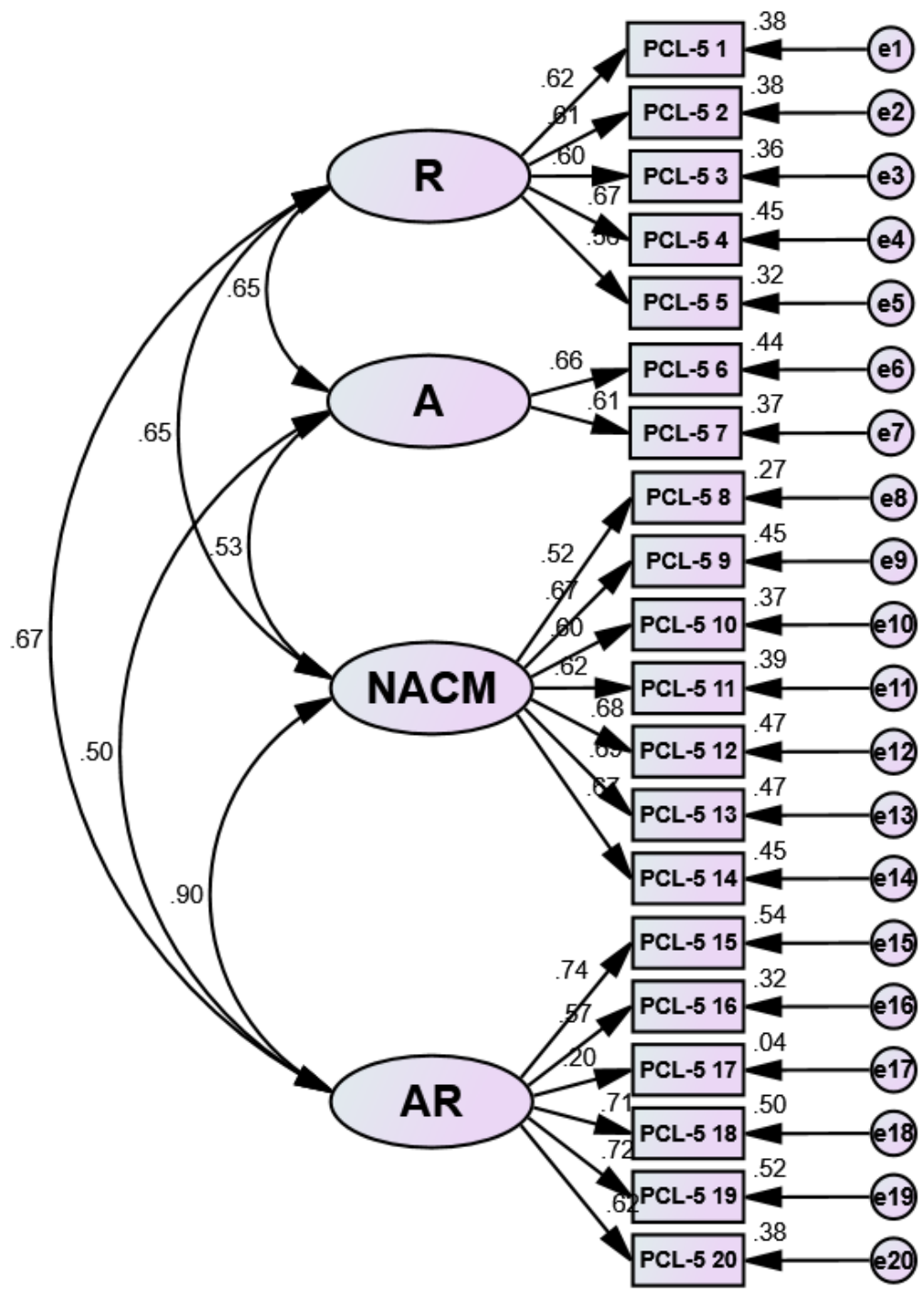

Figure 1

Structural equation modeling (SEM) of the DSM- 5 four-factor model 


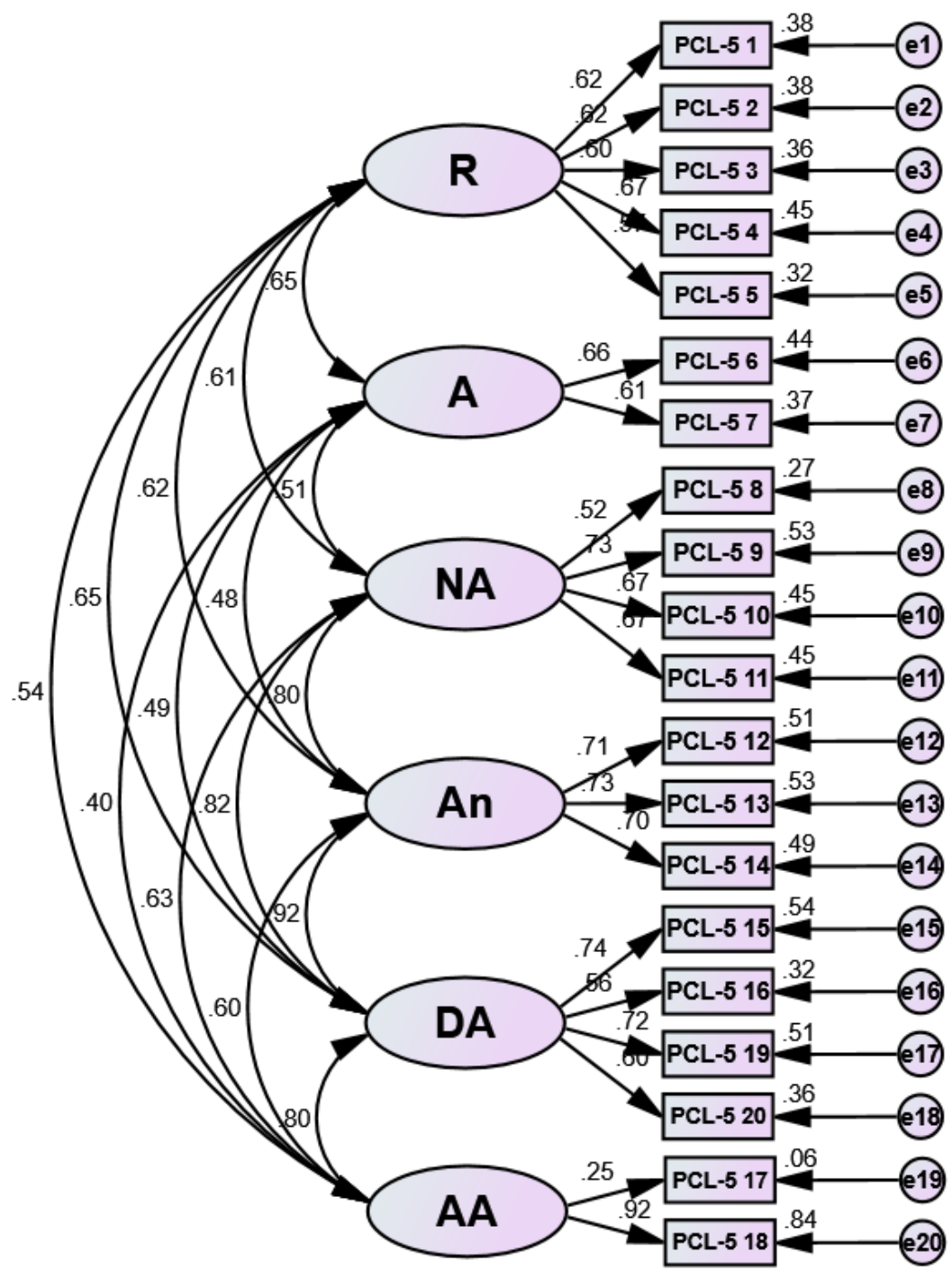

Figure 2

Structural equation modeling (SEM) of the six-factor Anhedonia model 


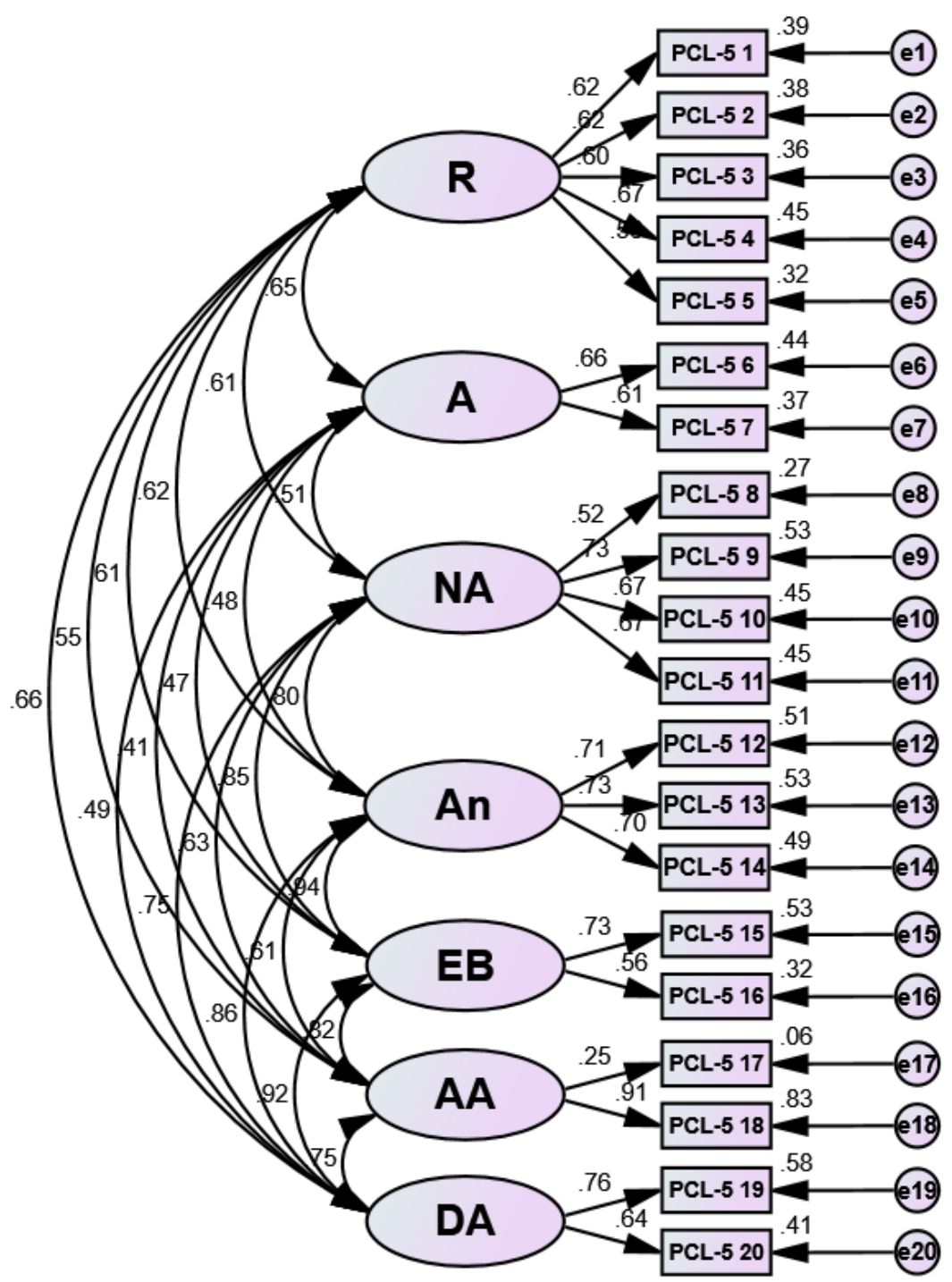

Figure 3

Structural equation modeling (SEM) of the seven-factor Hybrid model

\section{Supplementary Files}

This is a list of supplementary files associated with this preprint. Click to download. 
- Supplementarymaterial.docx

Page 23/23 